Print ISSN: 2233-4165 / Online ISSN: 2233-5382

doi:http://dx.doi.org/10.13106/ijidb.2018.vol9.no7.19

\title{
Interaction Effects of Lay Theories and Failure Type on Adaptive versus Compensatory Consumption Behavior*
}

\author{
Nak-Hwan Choi**, Li Wang***, Chang Chen**** \\ Received: June 14, 2018. Revised: June 28, 2018. Accepted: July 15, 2018.
}

\section{Abstract}

Purpose - This paper aims at exploring the effects of failure types such as failure in promotion orientation and failure in prevention orientation on consumers' consumption behavior, and the moderation role of lay theories in the effects.

Research design, data, and methodology - This study employed 2 between-subject designs(failure in promotion orientation vs. failure in prevention orientation) and also 2 (failure in promotion orientation vs. failure in prevention orientation) with implicit self as the within-subject. Chinese consumers participated in the empirical study, and to verify the hypotheses ANOVA, T-test and regression analysis were used.

Results - Consumers were more likely to choose adaptive consumption behavior rather than compensatory consumption behavior when they were encountered with failure in promotion orientation versus failure in prevention orientation. Lay theories did play the moderation role in the effect of failure types on consumption behavior. The incremental theorists who think that effort is an important way to accomplish their learning goals showed more willingness to conduct compensatory consumption behavior rather than adaptive consumption behavior.

Conclusions - Marketers should put more attention on the ways by which their products can help consumers self-improve when consumers encounter with failure. They should also be aware of the importance of consumers' mindsets when designing and developing advertising messages.

Keywords: Adaptive Consumption, Compensatory Consumption, Lay Theory, Self-regulation.

JEL Classifications: C83, L81, M31, P46.

\section{Introduction}

Based on self-regulatory focus theory, people's mindsets can be divided into promotion focus or prevention focus (Higgins, 1997, 1998). Promotion-oriented person may put more interested in hopes, wants and accomplishments to be

* This research was supported by "Research Base Construction Fund Support Program" funded by Chonbuk National University in 2018.

** First Author, Professor, Department of Business Administration, Chonbuk National University, Korea. E-mail: cnh@jbnu.ac.kr

*** Co-Author, Master, Chonbuk National University, Jeonju, Korea. E-mail: 5613819@naver.com

**** Corresponding Author, Doctoral Student, Chonbuk National University, Jeonju, Korea.

Tel: +82-63-270-2998, E-mail: 546285894@qq.com motivated to pursue positive outcomes. For example, the promotion-focused students tend to set up some goals above their current levels and then try to work hard to achieve them. In their eyes, they just feel non-gain when they experience failure. However, prevention-oriented persons show more attention to duty, responsibility and safety and are motivated to act in ways to avoid negative outcomes. To them, sometimes failure is loss rather than non-gain. That is, humans could be differently sensitive to failure according to their self-regulatory focus.

Failure-related consumption behavior can also be approached in view of negative emotions induced from self-deficits between actual self and ideal self. And negative emotions induced from these deficits might influence consumers' response behavior, such as compensatory consumption behavior and adaptive consumption behavior 
(Andrade, 2005). For example, after recognizing that a job seeker failed in the interview, he/she may tend to drink in order to escape from the negative mood states, which could be called as compensatory behavior; however, if he/she tend to buy some books to make up his/her shortcomings, then this book-buying behavior was regarded as adaptive consumption behavior. What kind of consumption behavior may consumers be more likely to choose when they are encountered with failures? There could be a significant difference in consumption behavior between when they face a failure in promotion orientation and when they do in prevention orientation. In the <Table 1>, however, previous research has focused on affective evaluation mechanism guiding behavior (Andrade, 2005), self-view-bolstering product choice under shaken self-view (Gao, Wheeler, \& Shiv, 2008), and self-discrepancies-driven consumer behavior (Mandel, Rucker, Levav, \& Galinsky, 2017), did not give much attention to the consumption difference between the two types of failure.

On the other side, this study also more concentrates on consumers themselves. Depending on lay theories, just because incremental theorists hold the opinion that the nature of their traits can be changed by effort, they might be associated with learning goals. However, since entity theorists do not think their nature of characteristics can be changed, they are more associated with performing goals. And when people fail in achieving their goals, incremental theorists may attribute the failure to insufficient effort while entity theorists may attribute it to the unintelligent. Rucker and Galinsky (2016) suggested that a variety of mindsets (e.g., regulatory focus, construal level, implementation versus deliberation, and power) could affect consumer behavior. Therefore the difference in consumption behavior between failures in promotion orientation and those in prevention orientation can be moderated by such lay theories as incremental theorists and entity theorists.

The purposes of this study are established as follows. First, it will explore the difference in compensatory versus adaptive consumption behavior between the two types of failure. Second, moderation role of the lay theories in the effects of the two types of failure on the compensatory versus adaptive consumption behavior will be explore.

\section{Theoretical Background and Hypotheses}

\subsection{Compensatory versus Adaptive Consumption Behavior}

\subsubsection{Compensatory Consumption Behavior}

Previous research has explored that people tend to engage in compensatory consumption as their defense mechanism when their aversive states are aroused or their self-views are shaken (Han et al., 2015; Kim \& Rucker, 2012; Mandel et al., 2017; McGregor et al., 2012; Proulx, 2012; Proulx \& Heine, 2010; Proulx et al., 2012; Rucker \& Galinsky, 2008; Rucker et al., 2012; Sivanathan \& Pettit, 2010; Tritt et al., 2012). For example, a girl who has just split up with her boyfriend may engage in shopping to emerge from bad moods. On the other hand, previous researchers have confirmed that emotions can affect how individuals process information and make decisions (Andrade, 2005). That is, consumers' behaviors are easier guided by negative emotions when they are encountered with self-deficits information. Exactly, not only can negative emotions drive individuals to consider the root cause of the problem and fix it, but also can motivate consumers to escape from the bad feelings. Then after humans' failing in achieving their goals, what takes effect on their consumption behaviors? And are there significant differences in consumption behaviors among different consumers?

Products can communicate information about the identities of their owners. It means consumers can show their self-image or talk with themselves by products, especially many popular brands products, such as Apple (exciting), Cartier (sophisticated) (Aaker, 1996). Also, people prefer to remove psychological discomfort through sacrificing money (Zhang, 2009). According to the demonstrations of consumption behavior researchers, consumers always show an increasing purchase intention for particular products when they encounter self-threats or self-deficits (Gao et al., 2008;

$<$ Table 1> A review of previous researches about mindsets

\begin{tabular}{|c|c|}
\hline Authors & Contents \\
\hline Andrade (2005) & affective evaluation mechanism and behavior \\
\hline Higgins (1998) & promotion focus, prevention focus and hedonic principle \\
\hline Gao, Wheeler, \& Shiv (2008) & shaken self and products choose \\
\hline Han, Duhachek, \& Rucker (2015) & $\begin{array}{c}\text { approach motivations and problem-focused coping, avoidance motivations and } \\
\text { emotion-focused coping }\end{array}$ \\
\hline Mandel, Rucker, Levav, \& Galinsky (2017) & $\begin{array}{l}\text { five distinct strategies: direct resolution, symbolic self-completion, dissociation, escapism, } \\
\text { and fluid compensation. }\end{array}$ \\
\hline Rucker \& Galinsky (2016) & a variety of mindsets and consumer behavior. \\
\hline Rucker \& Galinsky (2008) & power and signal status \\
\hline
\end{tabular}


Rucker \& Galinsky, 2008). Likewise, individuals tend to engage in consuming the status of product when they experience some upset feelings derived from the struggle between id and super-ego. The behavior that consumers buy a product or services over the original consumption level to cancel their frustrations can be called as compensatory consumption behavior. In generally, compensation process can be divided into three parts: (1) a tested difference between an individual's ideal and actual self, leading to (2) an evocative state of aversion, which ultimately drives the individual to engage in (3) compensatory actions (Mandel et al., 2017; Proulx et al., 2012). For instance, If a person is caught in a depressed state because of the failure in career, he is more likely to pursue psychological compensation by purchasing products such as a car or luxury watch with a symbol of power or status.

Just like Shen and Wyer's (2008) mentioned, consumers tend to show two different strategies when they are encountered with negative emotions, i.e., "problem-focused" and "emotion-focused" strategies. Specifically, the "emotion-focused" strategies mainly aims to reduce the negative feelings, which is similar to compensatory consumption behavior, such as overeating, excessive or over consumption (Shen \& Wyer, 2008). That is to say, the first reaction when individuals in the face of failure is to relieve their negative feelings. However, individuals who concentrate on "problem-focus" strategies tend to devote efforts to thinking over the cause of the problem and fix it, which is consistent with adaptive consumption behavior that we will mainly explain in the next part.

\subsubsection{Adaptive Consumption Behavior}

Some consumers tend to purchase services or products that can help them to self-improve when they are encountered with deficits, which is called adaptive consumption (Kim \& Gal, 2014). Different from compensatory consumption behavior, adaptive consumption behavior places more emphasis on the functions and attributes of products or services in improving themselves rather than on their symbolic values. As we mentioned before, "problem-focused" strategies are based on the reason why they got negative outcomes (Shen \& Wyer, 2008). For example, getting a poor grade on a test may make one consider seriously whatever factors result in this bad outcome instead of watching a funny movie. Generally, people who prefer to think of with "problem-focused" strategies tend to work harder after facing a failure. In marketing domain, consumers who have preference for "problem-focused" strategies are more likely to improve themselves by adaptive consumptions when they fall short of their goals or ideal states. Compared with "emotion-focused" strategies, the first reaction when individuals in the face of failure is to seek reasons for failure and change them.

\subsection{Two Types of Failure Based on Regulatory Focus Perspective}

\subsubsection{Self-deficits and Perceived Failure}

Generally speaking, individuals will feel happy, exciting when they achieved their goals, but feel sad, angry if their goals are not accomplished. What's more, individuals will engage in different consumption behaviors according to what emotions they felt. It is just because emotions could affect behaviors (Andrade, 2005). It means, humans will decrease the amount of ability for self-control, if their positive emotions are evoked (Rook \& Gardner, 1993). However, their negative emotions are more associated with systematic processing (Forgas, 1992; Schwarz \& Bless, 1991). Just like loss aversion, individual feels more sensitive to negative feelings than positive feelings. So in our article, we just talk about consumption behaviors when consumers perceived failure.

\subsubsection{Self-regulatory Theory}

In the regulatory focus theory (Higgins, 1997, 1998), human behavior can be divided into two parts according to individuals' mindsets (Rucker \& Galinsky, 2016): a promotion focus or a prevention focus. Unlike advancement, growth, and accomplishment where promotion-oriented individuals care about, prevention-oriented individuals pay more attention on responsibility, safety, and security. A person under a promotion-focused mindsets tends to improve him/herself as close as possible to ideal end-state, whereas a person with a prevention-focused mindsets attempts to get his/herself as far away as possible from an undesirable state. By the words of Carver and Scheier (2012), promotion-oriented mindset is a discrepancy-reducing tendency as an approach system dedicated to approach positive outcomes, and the another one is discrepancy-amplifying tendency as an avoidance system dedicated to avoid negative outcomes.

\subsubsection{Failure in Promotion Orientation}

A promotion focus pays attention to the "ideal" self, which is people's expectancy of self or other's wishes and expectations, or desirability (Pham \& Avnet, 2004). Combined with self-discrepancy theory, ideal self-regulatory aims to discrepancy-reducing, where discrepancies represent the absence of positive outcomes. In line with the opinion of psychology, ideal self-regulatory concentrates on the presence and absence of positive outcomes, and regards hopes, wishes and aspirations as maximal goals (Brendl \& Higgins, 1996). People with promotion focus have a goal of accomplishment, advancement and improvement, along with the motivation as close as possible to approaching positive state, outcome and gain (Higgins \& Tykocinski, 1992; Shah et al., 1998). When a promotion-oriented person experiences failure, he is more likely to perceive non-gain rather than 
loss because he just encountered the absence of a positive outcome, which means one did not obtain an ideal state. Thus, in a self-deficit situation, people focused on promotion get easily into the place of feeling deject-related emotions such like disappointment, sad and discouraged.

\subsubsection{Failure in Prevention Orientation}

A prevention focus pays more attention to the "ought" self, which is people's requirement of his/her responsibilities, duties and obligations (Pham \& Avnet, 2004). Combined with self-discrepancy theory, ought self-regulatory aims to discrepancy-amplifying where discrepancies represent the presence of negative outcomes. Also, consistent with psychological perspectives, ought self-regulatory focus on the absence and presence of negative outcomes, and consider duties, obligations and responsibilities as minimal goals (Brendl \& Higgins, 1996). Different from promotion-oriented individual's goals, prevention-oriented people care about duty, responsibility and assuring safety, along with motivation to get as far away as possible from negative state and loss (Higgins \& Tykocinski, 1992; Shah et al., 1998). When a prevention-oriented person experiences failure, he is more likely to perceive loss rather than non-gain because he straightly encountered the presence of a negative outcome, which means one did not complete his duties or responsibilities, and this failure may bring negative influence to others (e.g., Brockner \& Higgins, 2001; Higgins, 1997; Idson et al., 2000; Carver, 2009). And compared to the pain of perceiving the absence of one's maximal goal (non-gain), perceiving the defeat of one's minimal goal (loss) tend to get more intense pains than those in non-gain. Thus, in a self-deficit situation, people focused on prevention get easily into agitation-related emotions such like uneasy, tense and worried. What's more, individuals proved to be prone to present deactivation, reduced motivation, helplessness and withdrawal from approaching an ought goal when they faced prolonged failure (Dweck, 2013).

\subsubsection{Consumers' Response Differences between Failure Types}

As mentioned before, unlike individuals who successfully completed their goals tend to engage in heuristic processing (Forgas, 1992; Schwarz \& Bless, 1991), people who failed in achieving their goals are found to be associated with systematic processing (Forgas, 1992; Schwarz \& Bless, 1991) and tend to adopt either "problem-focus" or "emotion-focus" strategies usually depending on the current feelings. In details, researchers imply that people are more likely to adopt "problem-focus" strategies expecially when they deal with a high personal relevant and important event but fail in getting achievement. On the other hand, the self-determination theory also demonstrates that consumers usually attach more importance to adaptive consumption behavior rather than compensatory consumption behavior in their daily lifes, for it holds the opinion that humans are growth-oriented organisms with an innate psychological desires for competence, autonomy, and relatedness (Deci \& Ryan, 2000). In other word, humans have a tendency which arises from an inner psychological needs to choose and carry out something that can improve them or teach them something. Therefore, combined with either failure in promotion orientation or failure in prevention orientation, this study will propose that consumers who experienced strong negative emotions tend to adopt the "problem-focused" strategies and exhibit adaptive consumption behavior.

Although failure state could result in enhancing motivation or effort to overcome the negative states, it is worth noting that the relationship between mood and creativity demonstrated that promotion-oriented people have more strong association with creativity than prevention-oriented people. That is to say, a promotion focus holding flexibility and insight plays a problem-solving roles more than a prevention focus does (Baas et al., 2008). According to this theory, we propose that consumers are more likely to choose adaptive consumption behavior when they failed in promotion orientation rather than when they failed in prevention orientation. Those people encountered with a failure in promotion orientation tend to pay more attention to creativity, which may help them solve the problem and remove the aversive moods. Hence, formally,

$<\mathrm{H} 1>$ Consumers are more likely to choose adaptive consumption behavior rather than compensatory consumption behavior when they are encountered with failure in promotion orientation versus failure in prevention orientation.

\subsection{Lay Theories}

People can be divided into two categories according to their nature of characteristics regarded by themselves. And as shown in lay theories, entity theorists argue that human's characteristics are fixed and unchangeable, while incremental theorists regard their nature of characteristics as being changed through their efforts (Dweck, 2013). The lay or implicit theories can explain the differences in goal focus, perception of effort, attributions and brand preference.

Frist, according to social-cognitive model of motivation, entity theorists tend to show their worth and traits through positively evaluating their ability and refusing negative ones. Incremental theorists, by contrast, aim to increase their competence by conquering challenging tasks (Dweck, 2013).

Second, just because they have different ideals about nature of traits, their views of efforts are also different. So, unlike effort is low valued by entity theorists; incremental theorists pay more attention to efforts important in achieving their learning goal.

Third, there are many previous researches showing 
evidences to illustrate the strong influence of implicit self-theory on the achievement field, cognition and emotion domain behaviors when they meet the threat of failure (Dweck et al., 1995). For example, if they get bad marks, people under entity theorist may think they are stupid and they can't change it. However, people under incremental theorist may think they just did not make enough preparation and they can change it next time.

Fourth, as for brand preference, people under fixed mindsets prefer luxury brands, compared to people under growth mindsets. People who subscribe to entity theories need the symbolic nonfunctional value from luxury brands to enhance their self-signal. However, people who trust that they can change their traits by efforts, pay more attention to the functional value of brands.

Lay theories not only can be used to explain how people believe their nature of characteristics but also can be used to explain how they think about others' personalities (Yorkston et al., 2010). For instance, people who subscribe to entity theories are more sensitive to the ad such as "there is no better way to show others you have a modern sense of beauty" than the ad such as "there is no better way for you to learn how to have a modern sense of beauty." Thus entity theorists could have stronger purchase intentions due to the former ad. Incremental theorists, on the contrary, tend to choose the latter one, emphasize self-growth and functions of products in the ad (Park \& John, 2012).

\subsection{Lay Theories, Failure Type and Consumption Behavior}

People with different mindsets also show different thoughts, feelings and behaviors when they experience failure (Dweck et al., 1995). In addition, attribution theory also can explain the differences between entity theorists and incremental theorists when they fail in accomplishing their goals. Different attribution style will evoke different kinds of and level of emotions even when they meet the same failure. This is also one of the reason why some people tend to use the "problem-focus" strategies while some people tend to adopt the "emotion-focus" strategies.

Specifically, if incremental theorists experience failure, they may attribute it to insufficient effort instead of their natural characteristics. Because incremental theorists focus on learning goal, failure is acceptable and pardonable for them. Therefore, after being bit by failure, the moods experienced by incremental theorists may be aroused mildly because they know they can change their strategies or increase their effort for achieving the goal in the future. At this time, incremental theorists may engage in compensatory consumption behavior in order to remove their negative emotions and compensate the amount of effort consumers exerted, which is lined in with "emotion-focused" strategies.

What's more, increment theorists give a mastery-oriented response by increasing efforts when they experience failure. It means when facing different kinds of failure, incremental theorists would use different "problem-solving" strategies. As mentioned before, incremental theorists prefer a challenging work which is lined together with an ideal-self goal pursuit. Failure in promotion orientation usually takes place in not achieving one's ideal-self goal. In the face of this promotionoriented failure, people under growth mindsets may feel upset, especially when they recall the efforts that they have made but does not have work. However in the face of prevention-oriented failure, they may feel more worried, uneasy even tense because they neither realize their ideal goals nor achieve their ought goals. In another words, they loss their duty and responsibility even though they had put a lot of efforts. As a result, they are more likely to engage in compensatory behavior to compensate efforts their paid.

$<\mathrm{H} 2-1>$ Incremental theory-oriented consumers are more likely to choose compensatory consumption behavior rather than adaptive consumption behavior when they are encountered with a failure in prevention orientation versus when they are encountered with a failure in promotion orientation.

Different from incremental theorists, entity theorists are easy to attribute failure to their natural traits, therefore after failing in achieving the goal they tend to adopt "problem-focus" strategies and engage in adaptive consumption behavior even though they think they can not change their characteristics. A probable reason why entity theorists are likely to show willingness to exert effort when they experience failure is that they don't want other people to think them incapable or unintelligent since they always keep a performance goal of showing their ability. To convince others that the biggest reason for failure is just insufficient effort rather than their unability, entity theorists may tend to engage in adaptive consumption behavior. And just as mentioned before, a promotion focus holding more flexibility and insight plays a problem solving role than a prevention focus does, therefore we assume that entity theorists are more likely to engage in adaptive consumption behavior especially in the promotion-oriented failure.

$<\mathrm{H} 2-2>$ Entity theory-oriented consumers are more likely to choose adaptive consumption behavior rather than compensatory consumption behavior when they are encountered with a failure in promotion orientation versus when they are encountered with a failure in prevention orientation.

In sum, all the hypothesis in the research can be delineated by <Figure 1> 


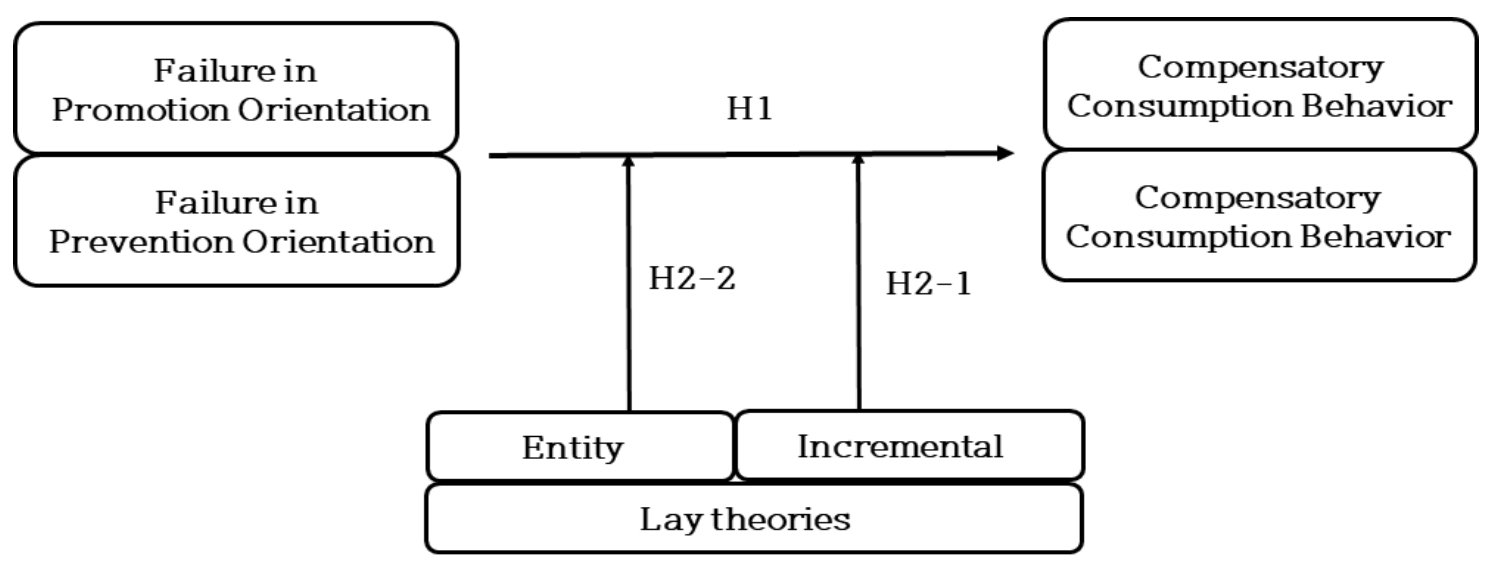

<Figure 1> Research Model

\section{Empirical Analysis}

\subsection{Pretest and Experimental Objects}

To measure whether consumers were induced to engage in compensatory/adaptive consumption behavior, our study needed to choose two kinds of representative products or services to reveal participants' behavior intention. Considering this, our study conducted a pretest referring to previous researches (e.g., Ruchker \& Galinsky, 2008). Specifically, we provided for 30 participants 10 kinds of products or services (IMAX, bookstore, Starbuks, Haagen-Dazs, Mengniu Dairy, New Oriental, Six Walnuts, HEYTEA, Fantawild Adventure and museum) and asked them to choose three kinds of products or services by using the questions "Which three kinds of products or services can best reflect consumers' needs for showing power and status?" and "Which three kinds of products or services can best reflect consumers' needs for self-improvement?". Finally, frequency analysis results showed that Haagen-Dazs $(86.6 \%)$, IMAX $(66.7 \%)$ and Fantawild $(59 \%)$ were the three kinds of products or services which were more likely to be considered as symbolic products or services while New Oriental (78\%), bookstore (63.3\%) and museum (50.9\%) were more likely to be considered as adaptive products or services.

Based on the result of this pretest and the failure type we designed, the IMAX as a compensatory product and the bookstore as an adaptive product were perceived to be more suitable for subsequent experiments. On the one hand, in generally speaking, students do not have independent economic sources. If they just failed at any event, they may not exhibit much willingness to choose some products or services which are much above their average level of daily consumption. So we deleted Fantawild and New Oriental. In order to diminish differences in consumption behavior intention between genders, we also deleted Haagen-Dazs and museum. On the other hand, because showing an increased willingness to purchase high-status or luxury products or services implies a compensatory consumption tendency (Ruchker \& Galinsky, 2008), our study finally adopted the IMAX with capability of revealing people's power, status and ability. Similarly, since showing an increased willingness to buy self-developing products or services implies an adaptive consumption tendency, we adopted the bookstore revealing people's belief to advancement and improvement.

\subsection{Study 1}

Study 1 aimed to explore consumers' consumption type differences between the two failure situations, that is, whether there is significant difference in individuals' consumption behavior between failure in promotion orientation and failure in prevention orientation. Thus, study 1 employed 2 (failure type: failure in promotion orientation vs. failure in prevention orientation) between-subject design to develope two categories of questionnaire.

\subsubsection{Measurements and Procedure}

\subsubsection{Failure Situation Manipulation and Measurements}

Even individuals' regulatory focus tend to be chronic (Higgins \& Silberman, 1998), researchers has found that both promotion and prevention mindsets can be activated straightly by experimental framing of two types of failure situations: a non-gain (promotion) and a loss (prevention) (Higgins \& Silberman, 1998). Hence, to let participants experience failure in promotion orientation (i.e., non-gain) and failure in prevention orientation (i.e., loss) separately, two types of failure scenario were developed.

First, the scenario to prime failure in promotion orientation was developed as follows. 
I am a student at an university, and I have studied English very hard, with the aim of exceeding the cut-off scores of 425 points and getting more than 550 points at the College English Test-Four so that I can get the qualification of subsequent speaking examination. I have devoted a lot of efforts to achieving my ideal goal such like eagerly spending time and energy in reciting important vocabularies, taking listening exercises and improving writing skills. I really attach great importance to this test, because it is important to me and doing well in this test will be helpful for my later job hunting after graduating.

Today, I was notified about the result of my test, and unfortunately I did not make it! My ideal goal was not realized! Even though I have studied so hard and diligently, I only just passed the exam by getting the cut -off score of 425 points. I feel frustrated, disappointed and even angry.

Second, the scenario to prime failure in prevention orientation was developed as follows.

I am a student at an university, and I have registered for the College English Test-Four. I know I should avoid getting less than the passing scores of 425 points. This is not only my duty as an undergraduate but also what our university required. In order to avoid a bad performance in the test, I have tried my best to avoid getting the loss that could happen to, and disturb me. I checked all my stationeries carefully to prevent from their going wrong and made an answer to each of question prudently. However, I did not control time in choosing the right answer and did not have time enough to check all of my answers from beginning to end, which made me not find out errors taken place in writing answers in the right position.

Finally, I was notified about the result of the test, and unfortunately / lost it! I failed in my duty! Looking at the grades of only 400 points, it seemed evidence that I was not enough considerable. I felt heavy in my chest, uneasy and even intensely agitated.

Following each scenario, there are several measurements to examine the manipulation of scenario.

Firstly, after showing the definition of promotion focus and prevention focus, we used one question "Please imagine you are in the situation of the scenario above, which regulatory focus do you think you are concentrating on?" on 7-point scale (1=promotion focus, 7=prevention focus) to examine whether participants were induced into a particular mindset orientation.

Next, to measure whether participants felt non-gain or loss in each scenario, we used a 7-point scale (1=non- gain-did not get my ideal goal, 7=loss-lost my ought ideal) by asking how participants felt after they were involved in each failure situation respectively.

Based on the demonstrations of Crowe and Higgins (1997), when facing a failure, people who hold a promotion focus can feel different negative moods compared to people holding a prevention focus. Then, to measure how much negative emotions have participants felt in each failure scenario respectively, we used four items: "I feel dejected (agitated)", "I fell discouraged (uneasy)", "I feel sad (tense)", "I feel disappointed (worried)" on 7-point scale (1=not at all, $7=$ very much) to examine negative moods of failure in promotion orientation (failure in prevention orientation) separately.

Finally, to measure the strength to which participants felt negative emotions, we used a 7-point scale (1=not strong at all, $7=$ very strong) in asking them how strong did they feel such feelings.

\subsubsection{Consumption Behavior Intention Measurements}

First, the study developed two kinds of products based the results of pretest to symbolize compensatory/adaptive consumption. Specifically, after giving a brief explanation about compensatory/adaptive consumption behavior, "Compensatory consumption behavior: consumers pursue self-pleasure by consumption in order to reduce or remove an inner state of being aversive" and "Adaptive consumption behavior: consumers pursue self-improvement by consumption in order to reduce or remove an inner state of being aversive", we used choice answer scale (1=compensatory, 2=adaptive) to each of the four items such as "IMAX cinema", "common bookstore", "IMAX cinema membership card", and "common bookstore membership card".

Next, to measure participants' consumption behavior tendency after they involved in a particular failure situation, we used three 7-point scales $(1=200 R M B$ worth of IMAX cinema membership card, $7=200 R M B$ worth of common bookstore membership card; 1=IMAX cinema, 7=common bookstore; 1=compensatory consumption, 7=adaptive consumption) to the question "What kind of product (or consumption) would you like to choose when encountering with the situation above?".

\subsubsection{Data Collection}

We conducted a survey online which focused only on Chinese consumers, and collected 100 questionnaires in total in which there were 50 questionnaires for each failure type. We deleted the questionnaires in which participants failed in being involved into either promotion focus or prevention focus at each corresponding failure situation, and 61 questionnaires were finally remained. The details of demographic figures were shown in $<$ Table $2>$. 
<Table 2> Demographic Information at Data for Study 1

\begin{tabular}{|c|c|c|c|}
\hline \multicolumn{2}{|c|}{ Variable } & Frequency & Percentage (\%) \\
\hline \multirow{3}{*}{ Gender } & Male & 24 & $39.3 \%$ \\
\cline { 2 - 4 } & Female & 37 & $60.7 \%$ \\
\hline \multirow{4}{*}{ Age } & Under 20 & 1 & $2.1 \%$ \\
\cline { 2 - 4 } & $21-30$ & 15 & $24.5 \%$ \\
\cline { 2 - 4 } & $31-40$ & 35 & $57.3 \%$ \\
\cline { 2 - 4 } & $41-50$ & 8 & $13.1 \%$ \\
\cline { 2 - 4 } & Over 50 & 2 & $3 \%$ \\
\hline \multirow{4}{*}{ Income } & Under $3000 \mathrm{RMB}$ & 2 & $3 \%$ \\
\cline { 2 - 4 } & $3000-6000 \mathrm{RMB}$ & 16 & $26.2 \%$ \\
\cline { 2 - 4 } & $6000-10000 \mathrm{RMB}$ & 36 & $59 \%$ \\
\cline { 2 - 4 } & Over $10000 \mathrm{RMB}$ & 7 & $11.8 \%$ \\
\hline \multicolumn{2}{|c|}{ Total Response } & 61 & $100 \%$ \\
\hline
\end{tabular}

\subsubsection{Results}

\subsubsection{Results of Identifying Two Types of Failure}

To examine whether our two types of failure scenario successfully activated participants' promotion focus or prevention focus separately, regression analysis was conducted where regular focus was made as dependent variable, and failure type was made as independent dummy variable. And results showed that two failure types were successfully manipulated $(\beta=-.169, t=-2.901, p<.05)$.

Similarly, to check whether consumers perceived loss (vs. non-gain) at failure in prevention focus (vs. failure in promotion focus), regression analysis was conducted where feeling (non-gain or loss) was made as dependent variable, and failure type was made as independent dummy variable. The results $(\beta=-.229, t=-3.77, p<.05)$ proved that consumers tend to perceive loss when encountered with failure in prevention orientation while perceive non-gain when encountered with failure in promotion orientation.

\subsubsection{Results of Analyzing the Consumption Difference}

T-Test was used to measure whether consumers exhibit consumption intention differences at each type of failure (failure in promotion orientation vs. failure in prevention orientation). And in order to explore casual relationship between failure types and consumption behavior intention, regression analysis was used. As shown in <Table $3>$ and $<$ Figure 2>, in the face of either failure in promotion orientation or prevention orientation, consumers were more likely to engage in adaptive consumption behavior. However, consumers were more interested in adaptive versus compensatory consumption behavior when they experience a failure in promotion orientation $(\mathrm{M}=5.54)$ rather than prevention orientation $(\mathrm{M}=5.14)(\mathrm{t}=2.419, \mathrm{p}<.05)$. And regression analysis showed the effect of failure type (dummy variable) on adaptive versus compensatory consumption was significant $(\beta=.300$, $\mathrm{p}<.05)$. Therefore, <hypothesis $1>$ was supported.

<Table 3> Results about the Difference

\begin{tabular}{|c|c|c|c|c|c|}
\hline \multirow{3}{*}{ T-Test } & Variable & Group & Mean & S.D. & Statistics \\
\hline & \multirow{2}{*}{ Consumption Behavior } & Failure in Promotion & 5.54 & .3864 & \multirow{2}{*}{$\mathrm{t}=2.419, \mathrm{p}=.019$, } \\
\hline & & Failure in Prevention & 5.14 & .8334 & \\
\hline \multirow[b]{2}{*}{$\begin{array}{c}\text { Regression } \\
\text { Analysis }\end{array}$} & Dependent Variable & Independent Variable & $\beta$ & $T$ & Statistics \\
\hline & $\begin{array}{l}\text { Adaptive vs. Compensatory } \\
\text { Consumption }\end{array}$ & Two types of failure & .300 & 2.419 & $\begin{array}{c}\mathrm{R} 2=.09 \\
\mathrm{~F}=5.852 \\
\mathrm{P}=.019\end{array}$ \\
\hline
\end{tabular}

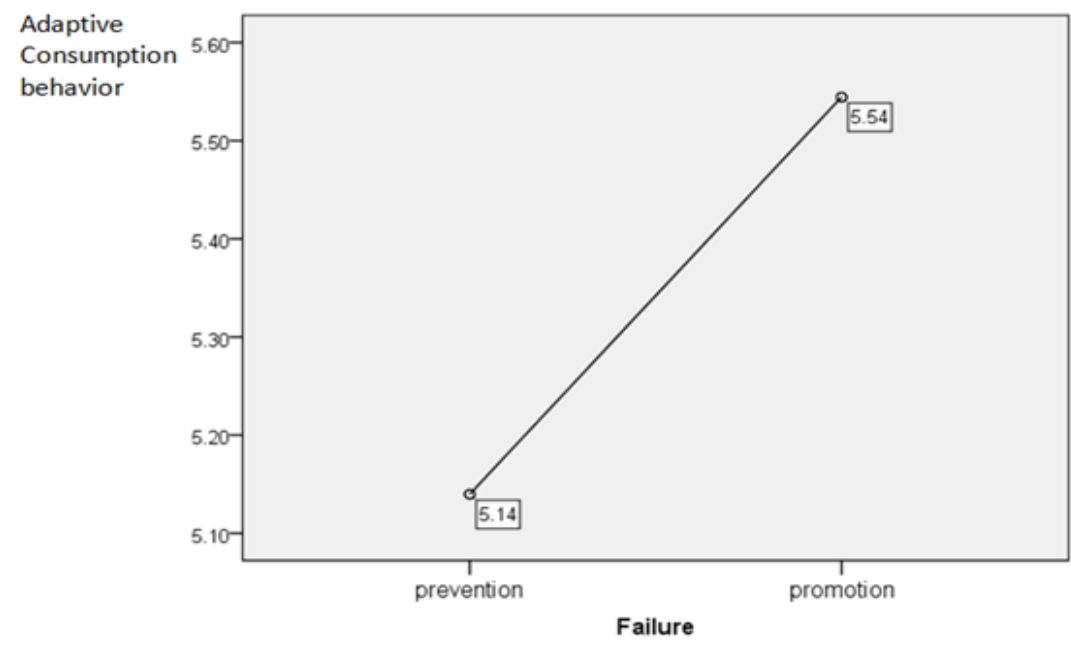

<Figure 2> Effects of Failure Types on Consumption Behavior 


\subsection{Study 2}

Study 2 aimed to explore the moderation role of consumers' implicit self (entity theorist vs. incremental theorist) in the effects of failure types on compensatory versus adaptive consumption behavior. Study 2 employed 2 (failure type: failure in promotion orientation vs. failure in prevention orientation) between-subjects design with implicit self as within-subject to develop two categories of questionnaire.

\subsubsection{Measurements and Procedure}

Except for adding the measurements of implicit self, study 2 adopted the same measurements and procedure as used in study 1. Consumers' implicit self was measured at the first place of questionnaire.

\subsubsection{Implicit-self Manipulation and Measurements}

The measurements of implicit mindsets were developed based on previous researches (Park \& Jonh, 2012). To reduce the possibility that participants think of themselves as incremental theorists while regard others as entity theorists, our study tried to develop a scale avoiding using "I" or "You" as subject. And because implicit selves always include many personal attributes, our research finally chose the domain-general measure of implicit theories (i.e., an implicit person theory measure) instead of the domain-specific measure (i.e., implicit intelligence theory measure; Dweck et al., 1995). Thus, our research finally used 4 items: " Everyone is a certain kind of person, and there is not much that they can do to really change that", "The kind of person someone is, is something basic about them, and it can't be changed very much", "People can do things differently, but the important parts of who they are can't really be changed", "People can't really change their deepest attributes" on 7-point scale (1=strongly disagree, 7=strongly agree) (Park \& John, 2012), with higher scores suggesting a stronger belief in incremental mindsets.

\subsubsection{Data Collection}

Similar to study 1 , we still conducted a survey online to collect 300 questionnaires in total in which there were 150 questionnaires for each failure type. We deleted the questionnaires in which participants failed to be involved in either promotion focus or prevention focus at corresponding failure situation, and 243 responses were remained finally. The details of demographic figures were shown in <Table $4>$.
$<$ Table 4> Demographic Information in Data for Study 2

\begin{tabular}{|c|c|c|c|}
\hline \multicolumn{2}{|c|}{ Variable } & Frequency & $\begin{array}{c}\text { Percentage } \\
\text { (\%) }\end{array}$ \\
\hline \multirow{3}{*}{ Gender } & Male & 81 & $33.3 \%$ \\
\cline { 2 - 4 } & Female & 162 & $66.7 \%$ \\
\hline \multirow{4}{*}{ Age } & Under 20 & 4 & $1.6 \%$ \\
\cline { 2 - 4 } & $21-30$ & 179 & $73.7 \%$ \\
\cline { 2 - 4 } & $31-40$ & 41 & $16.9 \%$ \\
\cline { 2 - 4 } & $41-50$ & 16 & $6.6 \%$ \\
\cline { 2 - 4 } & Over 50 & 3 & $1.2 \%$ \\
\hline \multirow{4}{*}{ Income } & Under 3000 RMB & 20 & $8.2 \%$ \\
\cline { 2 - 4 } & $3000-6000 \mathrm{RMB}$ & 75 & $30.9 \%$ \\
\cline { 2 - 4 } & $6000-10000 \mathrm{RMB}$ & 85 & $35.0 \%$ \\
\cline { 2 - 4 } & Over 10000 RMB & 63 & $25.9 \%$ \\
\hline \multicolumn{2}{|c|}{ Total Response } & 243 & $100 \%$ \\
\hline
\end{tabular}

\subsubsection{Results}

\subsubsection{Reliability and Validity}

To guarantee the convergent validity of items for each construct, principal component analysis based on Varimax in SPSS 22.0 program was conducted. As shown in <Table $4>$, there were two principal components which consist of implicit self (4 items) and consumers' consumption behavior (3 items).

And reliability analysis based on Cronbach's $\alpha$ was conducted to examine the internal consistency of items for each construct. The results in <Table 5> where all $\alpha>.7$ demonstrated a good internal consistency for each construct.

$<$ Table 5> Results of Analyzing Components

\begin{tabular}{|c|c|c|c|c|}
\hline \multirow{2}{*}{ Construct } & \multirow{2}{*}{ Item } & \multicolumn{2}{|c|}{ Component } & \multirow{2}{*}{$\boldsymbol{\alpha}$} \\
\cline { 2 - 4 } & & $\mathbf{1}$ & $\mathbf{2}$ & \\
\hline \multirow{3}{*}{$\begin{array}{c}\text { Consumption } \\
\text { behavior }\end{array}$} & behavior1 & .884 & .253 & \\
\cline { 2 - 4 } & behavior2 & .859 & .348 & \multirow{2}{*}{.895} \\
\cline { 2 - 4 } & behavior3 & .765 & .433 & \\
\hline \multirow{3}{*}{ Implicit self } & self1 & .165 & .881 & \\
\cline { 2 - 4 } & self4 & .435 & .732 & \multirow{2}{*}{.864} \\
\cline { 2 - 4 } & self3 & .501 & .692 & \\
\cline { 2 - 4 } & self2 & .441 & .685 & \\
\hline
\end{tabular}

\subsubsection{Results of Measuring Two Types of Failure}

Similar to the process of study 1 , we still used regression analysis to explore whether participants' promotion focus or prevention focus were successfully activated by each failure scenario. The results showed that two failure types were successfully manipulated ( $\beta=-.199, \mathrm{t}=-3.85, \mathrm{p}<.05)$.

Similarly, we also used regression analysis to inspect again whether our participants' self regulatory focus were successfully aroused, where feeling (non-gain or loss) was made as dependent variable, and failure types also was used as independent variable. The results $(\beta=-.196, t=-3.12$, 
p<.05) gave the evidence that participants perceived loss when encountered with failure in prevention orientation while feeling non-gain when encountered with promotion-oriented failure.

\subsubsection{Consumption Behavior Scores at Each Failure}

To measure consumers' consumption behavior scores at each failure situation, implicit self was divided into incremental self and entity self by calculating the means of four implicit self items scores and marking "incremental self" when the means are below 4 while marking "entity self" when the means are above 4. Thus, there are final four groups (incremental theorists in failure in promotion orientation, incremental theorists in failure in prevention orientation, entity theorists in failure in promotion orientation, entity theorists in failure in prevention orientation). Then, two-way ANOVA was conducted. As exhibited in <Table 6> and <Figure 3>, incremental theory-oriented consumers were more likely to choose compensatory consumption behavior, in view of both of the consumption behavior scores of incremental theorists in failure in promotion orientation $(\mathrm{M}=3.09)$ and those in failure in prevention orientation $(\mathrm{M}=2.09)$.

However, entity theory-oriented consumers were more likely to choose adaptive consumption behavior no matter whether they were encountered with failure in promotion focus $(M=5.31)$ or failure in prevention focus $(M=5.38)$.
$<$ Table 6> Consumption Behavior Scores at Each Group

\begin{tabular}{|c|c|c|c|c|}
\hline Failure & Self & Mean & Std. Deviation & $\mathbf{N}$ \\
\hline \multirow{4}{*}{ Prevention } & Incremental & 2.0926 & .82659 & 36 \\
\cline { 2 - 5 } & Entity & 5.3763 & .83872 & 93 \\
\cline { 2 - 5 } & Total & 4.4599 & 1.69671 & 129 \\
\hline \multirow{4}{*}{ Promotion } & Incremental & 3.0909 & 1.32621 & 33 \\
\cline { 2 - 5 } & Entity & 5.3086 & .90489 & 81 \\
\cline { 2 - 5 } & Total & 4.6667 & 1.44856 & 114 \\
\hline \multirow{3}{*}{ Total } & Incremental & 2.5700 & 1.19654 & 69 \\
\cline { 2 - 5 } & Entity & 5.3448 & .86826 & 174 \\
\cline { 2 - 5 } & Total & 4.5569 & 1.58529 & 243 \\
\hline
\end{tabular}

\subsubsection{Testing Interaction Effects}

Followed with the consumption behavior scores at each group, we straightly explored the interaction effects of failure type and lay theories on consumption behavior. Because both of the independent variable (failure types) and moderation variable (incremental self vs. entity self) are nonmetric variables, two-way ANOVA was adopted to text interaction effects. And the results $(F 1,239=15.900, p<.05$, $\mathrm{R} 2=.654$ ) shown in $<$ Table $7>$ demonstrates that lay theories consumers hold play a significant moderating role in the effects of failure type on consumption behavior.

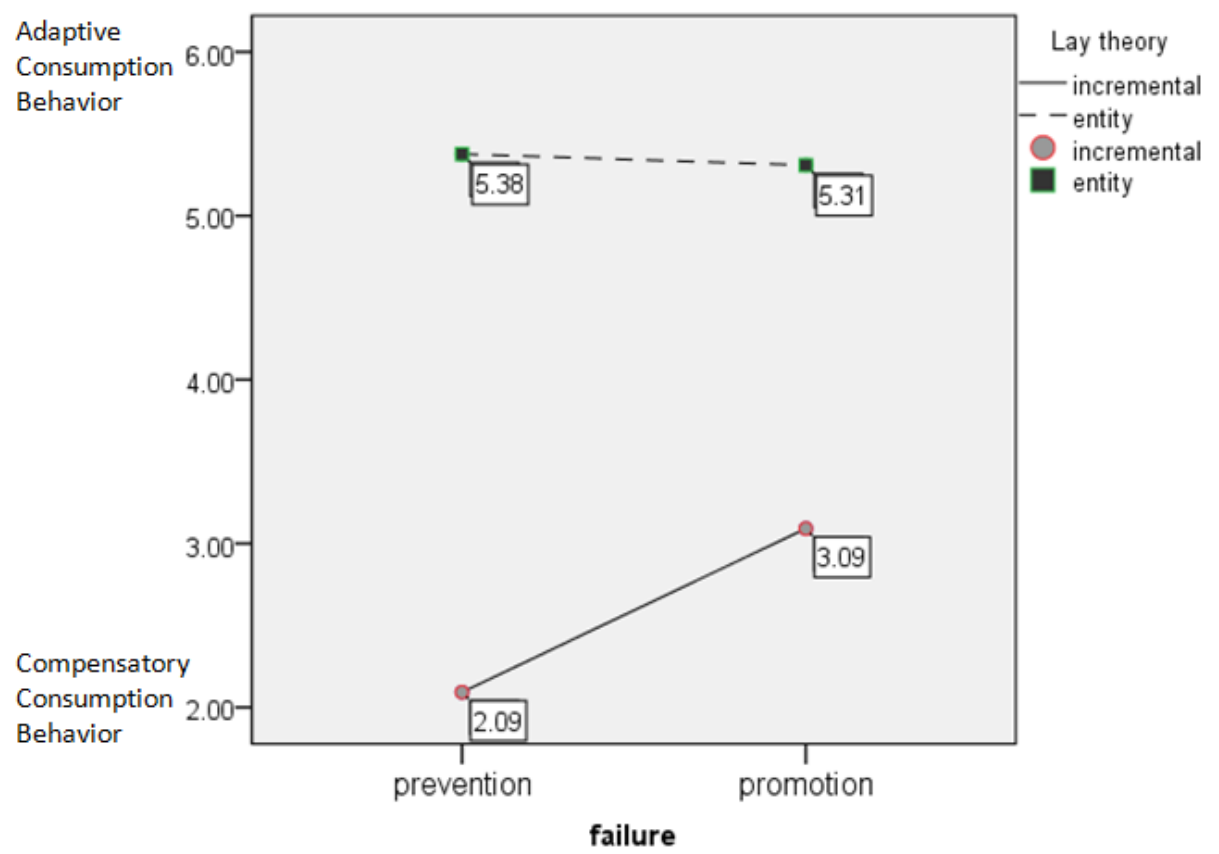

<Figure 3> The Interaction Effects of Failure Types and Lay Theories 
$<$ Table 7> Results of Analyzing the Interaction Effects

\begin{tabular}{|c|c|c|c|c|c|}
\hline Source & Type III Sum of Squares & df & Mean Square & F & Sig. \\
\hline Corrected Model & $397.765 a$ & 3 & 132.588 & 150.597 & .000 \\
\hline Intercept & 3101.890 & 1 & 3101.890 & 3523.210 & .000 \\
\hline Failure Type (a) & 10.668 & 1 & 10.668 & 12.117 & .001 \\
\hline Lay theory (b) & 372.834 & 1 & 372.834 & 423.474 & .000 \\
\hline $\mathrm{a}^{*} \mathrm{~b}$ & 13.999 & 1 & 13.999 & 15.900 & .000 \\
\hline Error & 210.419 & 239 & .880 & & \\
\hline Total & 5654.222 & 243 & & & \\
\hline Corrected Total & 608.185 & 242 & & & \\
\end{tabular}

a: $\mathrm{R}$ Squared $=.654$ (Adjusted $\mathrm{R}$ Squared $=.650$ )

<Table 8> Results of Failure Types and Lay Theories on the Effects of Consumption Behavior

\begin{tabular}{|c|c|c|c|c|c|}
\hline Source & Group III Sum of Squares & df & Mean Square & $\mathbf{F}$ & Sig. \\
\hline Corrected Model & $397.765 a$ & 3 & 132.588 & 150.597 & .000 \\
\hline Intercept & 3101.890 & 1 & 3101.890 & 3523.210 & .000 \\
\hline Group & 397.765 & 3 & 132.588 & 150.597 & .000 \\
\hline Error & 210.419 & 239 & .880 & & \\
\hline Total & 5654.222 & 243 & & & \\
\hline Corrected Total & 608.185 & 242 & & & \\
\hline
\end{tabular}

a: $\mathrm{R}$ squared $=.654$ (adjusted $\mathrm{R}$ squared $=.650$ )

$<$ Table 9> Multiple Comparison in Testing Interaction Effect

\begin{tabular}{|c|c|c|c|c|c|c|}
\hline \multirow{2}{*}{ (I) Group } & \multirow{2}{*}{ (J) Group } & \multirow{2}{*}{ Mean Difference (I-J) } & \multirow{2}{*}{ S.E } & \multirow{2}{*}{ Sig. } & \multicolumn{2}{|c|}{ 95\% Confidence Interval } \\
\hline & & & & & Lower Bound & Upper Bound \\
\hline \multirow{3}{*}{ pro-incre } & pre-incre & $.9983^{*}$ & .22613 & .000 & .3616 & 1.6350 \\
\hline & pre-entity & $-2.2854^{*}$ & .19012 & .000 & -2.8207 & -1.7501 \\
\hline & pro-entity & $-2.2177^{*}$ & .19377 & .000 & -2.7633 & -1.6722 \\
\hline \multirow{3}{*}{ pro-entity } & pre-incre & $3.2160^{*}$ & .18795 & .000 & 2.6869 & 3.7452 \\
\hline & pro-incre & $2.2177^{*}$ & .19377 & .000 & 1.6722 & 2.7633 \\
\hline & pre-entity & -.0677 & .14260 & .973 & -.4692 & .3338 \\
\hline \multicolumn{7}{|c|}{$\begin{array}{l}\text { Based on observed means. } \\
\text { The error term is Mean Square(Error) }=.880 \text {. }\end{array}$} \\
\hline
\end{tabular}

\subsubsection{Multiple Comparison in Testing Hypotheses}

To further explore the specific differences among those 4 groups, a multiple comparison was conducted in ANOVA. According to the particular differences demonstrated in $<$ Table $8>$ and $<$ Table $9>$, even though study 1 has proved that consumers are more likely to choose adaptive consumption behavior compared to compensatory behavior especially when they are encountered with failure in promotion orientation (vs. failure in prevention orientation), this effect is significantly moderated by lay theories consumers hold $(\mathrm{F} 3,239=150.597, \quad \mathrm{p}<.05)$. Specifically, incremental theorists are more likely to choose compensatory consumption behavior especially when they are encountered with failure in prevention orientation $(\mathrm{M}=2.09)$ (vs. failure in promotion orientation $(\mathrm{M}=3.09) \quad(\mathrm{MD}=.9983, \mathrm{P}<.05)$, that is, incremental theory holden by consumers plays a weaken moderating role in the effect of failure type on consumption behavior, which supports <hypothesis 2-1>.

On the contrary, entity theorists are more likely to choose adaptive consumption behavior both when they face a failure in promotion orientation $(M=5.31)$ and prevention orientation $(\mathrm{M}=5.38) \quad(\mathrm{MD}=-.0677, \quad \mathrm{P}>.05) \quad$ compared to incremental theorists (all of $\mathrm{p}<.05$ ), hypothesis $2-2$ is not supported. Compared to study 1 , when consumers' fixed mindsets are aroused, they exhibit differences in consumption behavior both when they faced failure in promotion orientation $(M=5.31<5.54)$, and failure in prevention orientation $(M=5.38>5.14)$, that is, entity theory holden by consumers plays a partial strength of moderating role in the effects of failure type on consumption behavior. 


\section{Discussion and Conclusion}

\subsection{Research Summary}

In our study, we explored lay theories as a moderator in the effects of two types of failure on consumers' consumption behavior. In order to reflect consumers' real behavior intention after meeting with two types of failure as much as possible, our research carried out three experiments. In the first part of study, we used ten kinds of products or services to measure whether consumers were induced to have compensatory or adaptive consumption behavior and finally chose the IMAX as a represent of compensatory product and the bookstore as a represent of adaptive product through frequency analysis of consumers' purchase intention. Next, in the second part of study, we manipulate two types of failure (failure in promotion orientation vs. failure in prevention orientation) to measure whether there is a signigicant difference in choosing consumption behavior. At last, we employed 2 (failure type: failure in promotion orientation vs. failure in prevention orientation) between-subjects designed with implicit self as within-subject to develop two categories of questionnaire to explore whether lay theories can moderate the effects of two types of failure on consumers' consumption behavior. In particular, the results of our study are summarized as followings.

Firstly, consumers who failed in achieving a goal important to them did show difference in their subsequent consumption behaviors. Concretely, study 1 shows that if consumers experience failure, they tend to engage in adaptive consumption behavior rather than compensatory consumption behavior. And compared with a failure in prevention orientation, consumers show more willingness to choose adaptive consumption behavior when encountered with a failure in promotion orientation.

Secondly, lay theories plays a moderating role in the effects of two types of failure on consumption behaviors. Specifically, combining the results of study 1 and study 2 , entity theory plays a partial strength of moderating role while incremental theory plays a weak moderating role in that process.

Thirdly, consumers who subscribe to the views that their nature of characteristics can be changed, are more likely to engage in compensatory consumption behavior especially when they experience a failure in prevention orientation rather than a failure in promotion orientation.

Fourth, consumers who agree with their nature of characteristics can not be changed (i.e., entity theorists), are more likely to engage in adaptive consumption behavior.

\subsection{Theoretical Implication}

The current study aims to research the relationships among two types of failure, lay theories and consumers' consumption behaviors. Thus, there are two theoretical implication contributed by the current study as following:

Firstly, our research demonstrates how lay theories have moderating influences on the effect of two types of failure on consumers' consumption behavior. In other words, the current research practices lay theories (Dweck, 2013), which can be called as implicit theories or mindset theories. Specially in the part of marketing, even entity theorists pay less attention to efforts, they still tend to engage in adaptive consumption behavior rather than compensatory consumption behavior when they are facing failure. The interesting thing is incremental theorists showing more willingness to conduct compensatory consumption behavior who trust that effort is an important way for them to accomplish their learning goals.

Secondly, in spite of lay theories, we find that even suffering from negative emotions induced from failing to achieve a goal, consumers still exhibit more intentions to adaptive consumption behavior instead of compensatory consumption behavior. That is, the current study not only practices the self-determination theory (Deci \& Ryan, 2000), but also proves that humans always keep an inner desire to make their growth regardless of whether they are encountered with a failure in promotion orientation or a failure in prevention orientation.

\subsection{Managerial Implication}

Based on the outcomes of our study, we learn about the relationship between mindsets, emotion states, "problemfocus" or "emotion-focus" strategies and purchase intentions. Therefore, we can offer some suggestions to marketers.

On one hand, according to our results of study 1 and self-determination theory (Deci \& Ryan, 2000), humans' inner state of psychological needs push them to do something which can make them better no matter in the face of promotion-oriented failure or prevention-oriented failure. Based on this finding, marketers should put more attentions on the function of how their products can help consumers self-improve when they designed the products advertisements or brand slogan, such like 'Keep Moving (ANTA)'.

On the other hand, according to our result of study 2 and lay theories, salesperson may feel difficult in identifying whether consumers belong to fixed mindsets or growth mindsets at first sight, therefore keeping an eye on consumers' emotions becomes a good way in predicting their behavior intention(Park, Kim, Kim, \& Han, 2015). Meanwhile, even though consumers' mindsets tend to be chronic and stable, it is effective to prime their goal regulatory focus as well as growth/fixed mindsets through particular advertising messages. Therefore, marketers should be awareness of the importance of consumers' mindsets when designing and developing advertising messages. 


\subsection{Limitations and Directions for Future Research}

There are several limitations in our research that could be explored in the future.

Firstly, in our research we just focused on the relationship between consumers' purchase intention and types of failure, but did not investigate the relationship between consumers' purchase intention and types of self-focused success(Choi \& Liu, 2014; Choi, 2016). Therefore future research is encouraged to research consumers' behavioral response to the success, and their consumption differences between failure and success also can be studied in the further research.

Secondly, through the current research, we mentioned the relationship between mood states and consumers' behavior, but did not consider the level of negative emotions aroused and differences between negative emotions, such as sad or upset, anger or tensive(Choi, Oyunbileg, \& Tsogtbayar, 2015). Therefore, the interaction of arousal levels and valence in the consumers' responses to failure or success also can be studied in the further study.

Finally, our experimental subjects are only Chinese, so we can not know whether the differences in the consumption behavior varies from culture to culture. This could be an interesting research subject for future research.

\section{References}

Aaker, D. A. (1996). Building Strong Brands. New York: Free Press.

Andrade, E. B. (2005). Behavioral consequences of affect: Combining evaluative and regulatory mechanisms. Journal of Consumer Research, 32(3), 355-362.

Baas, M., De Dreu, C. K., \& Nijstad, B. A. (2008). A meta-analysis of 25 years of mood-creativity research: Hedonic tone, activation, or regulatory focus?. Psychological Bulletin, 134(6), 779-806.

Brendl, C. M., \& Higgins, E. T. (1996). Principles of judging valence: What makes events positive or negative?. Advances in Experimental Social Psychology, 28, 95-160.

Brockner, J., \& Higgins, E. T. (2001). Regulatory focus theory: Implications for the study of emotions at work. Organizational behavior and human decision processes, 86(1), 35-66.

Carver, C. S., \& Scheier, M. F. (2012). Attention and self-regulation: A control-theory approach to human behavior. New York: Springer Science \& Business Media.

Carver, C. S. (2009). Threat sensitivity, incentive sensitivity, and the experience of relief. Journal of Personality, 77(1), 125-138.
Choi, N. H. (2016). Attribution of goal achievement to efforts and traits according to pride types and lay theory. Journal of Distribution Science, 14(2), 57-63.

Choi, N. H., \& Liu, C. (2014). The effects of self-referencing and counteractive construal on consumption goal reversion. Journal of Distribution Science, 12(3), 5-13.

Choi, N. H., Oyunbileg, T., \& Tsogtbayar, N. (2015). The effect of ambient sadness on hedonic choice. Journal of Distribution Science, 13(3), 11-19.

Crowe, E., \& Higgins, E. T. (1997). Regulatory focus and strategic inclinations: Promotion and prevention in decision-making. Organizational behavior and human decision processes, 69(2), 117-132.

Deci, E. L., \& Ryan, R. M. (2000). The "what" and "why" of goal pursuits: Human needs and the self-determination of behavior. Psychological Inquiry, 11(4), 227-268.

Dweck, C. S. (2013). Self-theories: Their Role in Motivation, personality, and Development. Philadelphia, PA : Psychology Press.

Dweck, C. S., Chiu, C. Y., \& Hong, Y. Y. (1995). Implicit theories and their role in judgments and reactions: A word from two perspectives. Psychological Inquiry, 6(4), 267-285.

Forgas, J. P. (1992). Affect in social judgments and decisions: A multiprocess model. Advances in Experimental Social Psychology, 25, 227-275.

Gao, L., Wheeler, S. C., \& Shiv, B. (2008). The "shaken self": Product choices as a means of restoring self-view confidence. Journal of Consumer Research, 36(1), 29-38.

Han, D., Duhachek, A., \& Rucker, D. D. (2015). Signaling status with luxury goods: The role of brand prominence. Journal of Marketing, 74(4), 15-30.

Higgins, E. T. (1997). Beyond pleasure and pain. American Psychologist, 52(12), 1280-1300.

Higgins, E. T. (1998). Promotion and prevention: Regulatory focus as a motivational principle. Advances in Experimental Social Psychology, 30, 1-46.

Higgins, T., \& Tykocinski, O. (1992). Self-discrepancies and biographical memory: Personality and cognition at the level of psychological situation. Personality and Social Psychology Bulletin, 18(5), 527-535.

Higgins, E. T., \& Silberman, I. (1998). Development of regulatory focus: Promotion and prevention as ways of living. In J. Heckhausen, \& C. S. Dweck (Eds.), Motivation and Self-Regulation Across the Life Span (pp. 78-113). New York, NY: Cambridge 
University Press.

Idson, L. C., Liberman, N., \& Higgins, E. T. (2000). Distinguishing gains from nonlosses and losses from nongains: A regulatory focus perspective on hedonic intensity. Journal of Experimental Social Psychology, 36(3), 252-274.

Kim, S., \& Gal, D. (2014). From compensatory consumption to adaptive consumption: The role of self-acceptance in resolving self-deficits. Journal of Consumer Research, 41(2), 526-542.

Kim, S., \& Rucker, D. D. (2012). Bracing for the psychological storm: Proactive versus reactive compensatory consumption. Journal of Consumer Research, 39(4), 815-830.

Mandel, N., Rucker, D. D., Levav, J., \& Galinsky, A. D. (2017). The compensatory consumer behavior model: How self-discrepancies drive consumer behavior. Journal of Consumer Psychology, 27(1), 133-146.

McGregor, I., Prentice, M., \& Nash, K. (2012). Approaching relief: Compensatory ideals relieve threat-induced anxiety by promoting approachmotivated states. Social Cognition, 30(6), 689-714.

Park. E. J., Kim, C. G., Kim, M. S., \& Han, J. H. (2015). Justice and authenticity of service recovery: Effects on customer behavioral intention. Journal of Distribution Science, 13(2), 63-73.

Park, J. K., \& John, D. R. (2012). Capitalizing on brand personalities in advertising: The influence of implicit self-theories on ad appeal effectiveness. Journal of Consumer Psychology, 22(3), 424-432.

Pham, M. T., \& Avnet, T. (2004). Ideals and oughts and the reliance on affect versus substance in persuasion. Journal of Consumer Research, 30(4), 503-518.

Proulx, T. (2012). Threat-compensation in social psychology: Is there a core motivation?. Social Cognition, 30(6), 643-651.

Proulx, T., \& Heine, S. J. (2010). The frog in Kierkegaard's beer: Finding meaning in the threat compensation literature. Social and Personality Psychology Compass, 4(10), 889-905.

Proulx, T., Inzlicht, M., \& Harmon-Jones, E. (2012).
Understanding all inconsistency compensation as a palliative response to violated expectations. Trends in Cognitive Sciences, 16(5), 285-291.

Rook, D. W., and Gardner, P. G. (1993). In the mood: Impulse buying's affective antecedents. Research in Consumer Behavior, 6(7), 1-28.

Rucker, D. D., \& Galinsky, A. D. (2016). Growing beyond growth: Why multiple mindsets matter for consumer behavior. Journal of Consumer Psychology, 26(1), 161-164.

Rucker, D. D., \& Galinsky, A. D. (2008). Desire to acquire: Powerlessness and compensatory consumption. Journal of Consumer Research, 35(2), 257-267.

Rucker, D. D., Galinsky, A. D., \& Dubois, D. (2012). Power and consumer behavior: How power shapes who and what consumers value. Journal of Consumer Psychology, 22(3), 352-368.

Schwarz, N., \& Bless, H. (1991). Happy and mindless, but sad and smart? The impact of affective states on analytic reasoning. Emotion and social Judgments, 23, 55-71.

Shah, J., Higgins, T., \& Friedman, R. S. (1998). Performance incentives and means: How regulatory focus influences goal attainment. Journal of Personality and Social Psychology, 74(2), 285-293.

Shen, H., \& Wyer, R. S. (2008). The impact of negative affect on responses to affect-regulatory experiences. Journal of Consumer Psychology, 18(1), 39-48.

Sivanathan, N., \& Pettit, N. C. (2010). Protecting the self through consumption: Status goods as affirmational commodities. Journal of Experimental Social Psychology, 46(3), 564-570.

Tritt, S. M., Inzlicht, M., \& Harmon-Jones, E. (2012). Toward a biological understanding of mortality salience (and other threat compensation processes). Social Cognition, 30(6), 715-733.

Zhang, L. (2009). An exchange theory of money and self-esteem in decision making. Review of General Psychology, 13(1), 66-76. 